\title{
National survey of availability of physical rehabilitation services in Iran: A mixed methods study
}

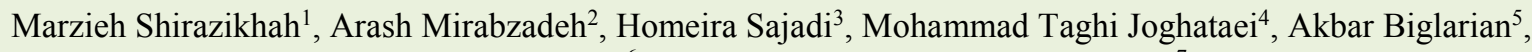
Tahmineh Mousavi $^{6}$, Farahnaz Mohammadi Shahboulaghi ${ }^{7}$

${ }^{1}$ MD, MPH, Ph.D., Candidate of Social Determinants of Health Research Center, University of Social Welfare and Rehabilitation Sciences, Tehran, Iran

${ }^{2}$ MD of Psychiatry, Professor, Social Determinants of Health Research Center, Psychiatry Department, University of Social Welfare and Rehabilitation Sciences, Tehran, Iran

${ }^{3}$ MD of Community Medicine, Associate Professor of Social Welfare Management Research Center, University of Social Welfare and Rehabilitation Sciences, Tehran, Iran

${ }^{4} \mathrm{Ph} . \mathrm{D}$. of Neuroscience, Professor, Department of Anatomy and Neuroscience, Cellular and Molecular Research

Center, School of Medicine, Iran University of Medical Sciences, Tehran, Iran

${ }^{5}$ Ph.D. of Biostatistics, Associate Professor, Department of Biostatistics, University of Social Welfare and Rehabilitation Sciences, Tehran, Iran

6 Ph.D. of Occupational Therapy, Assistant Professor, Department of Occupational Therapy, School of Rehabilitation, Tehran University of Medical Sciences, Tehran, Iran

${ }^{7}$ Ph.D. of Nursing, Associate Professor, Social Determinants of Health Research Center, Nursing Department, University of Social Welfare and Rehabilitation Sciences, Tehran, Iran

\section{Type of article: Original}

\begin{abstract}
Background: The prevalence of disability in Iran has increased due to ageing of the population and the presence of chronic diseases. However, little is known about the availability of rehabilitation services in Iran.

Objective: To study the availability of physical rehabilitation services in Iran.

Methods: This was a mixed method study. In the first phase, a qualitative design was conducted for designing an instrument with focus groups based on Service Availability and Readiness Assessment (SARA) instrument (developed by World Health Organization). Content analysis was used for data analysis. Then, in the second phase, a cross-sectional study was performed to collect the data with census method in Iran. This study was formed from June to October 2015, and samples consisted of all governmental, public non-governmental and private facilities established for rehabilitation centers affiliated with the Ministry of Health and Medical Education, Ministry of Labor, Cooperative and Social Welfare and the Iranian Red Crescent Society. Data analyses were performed using SPSS software (version 16). Descriptive statistical analysis (percentage and frequency) were calculated for quantitative data.

Results: In the first phase, the content analysis of qualitative data identified a Master Facilities List (MFL) of rehabilitation services and service providers in Iran. Results of the second phase showed that the rate of inpatient, outpatient, community-based and long-term care centers per 1,000,000 populations in Iran were 1.68, 89.24, 66.21 and 3.6, respectively. Also, that the rate of rehabilitation professionals including physical medicine and rehabilitation specialists, physiotherapists, occupational therapists, speech therapists, and audiologists were 3.90, $64.65,22.09,22.83$ and 24.18 per $1,000,000$ populations, respectively.

Conclusion: There is a need to increase the availability of rehabilitation services and to promote rehabilitation referrals by using an interdisciplinary team approach.

Keywords: Iran, Rehabilitation services, Rehabilitation professionals, Availability
\end{abstract}

\section{Corresponding author:}

Associate Professor Dr. Farahnaz Mohammadi Shahboulaghi, Social Determinants of Health Research Center, Nursing Department, University of Social Welfare and Rehabilitation Sciences, Tehran, Iran. Tel: +982122180036, Fax:+982122180121, Email: mohammadifarahnaz@gmail.com

Received: July 19, 2017, Accepted: September 02, 2017, Published: November 2017

iThenticate screening: August 21, 2017, English editing: October 15, 2017, Quality control: November 12, 2017

This article has been reviewed / commented by three experts

(C) 2017 The Authors. This is an open access article under the terms of the Creative Commons Attribution-NonCommercialNoDerivs License, which permits use and distribution in any medium, provided the original work is properly cited, the use is non-commercial and no modifications or adaptations are made. 


\section{Introduction \\ 1.1. Background}

Almost one billion individuals (15\% of the world's population) suffer from some form of disability. Accordingly, it is estimated that more than 11 million individuals in Iran are disabled and need rehabilitation services (1). Rehabilitation services can significantly help people with or at risk of disability to achieve optimal performance in their given environment (2). In Iran, the Ministry of Health and Medical Education, the Ministry of Labor, Cooperative and Social Welfare, and the Iranian Red Crescent Society provide rehabilitation services in different settings such as inpatient, outpatient, community-based, nursing home, and respite care centers (3-5). The Iranian government has intended to extend health service coverage in recent years. Based on the existing literature, potential coverage includes the availability, accessibility, and acceptability of the services provided (6). Availability refers to the physical presence of the health services, including health infrastructure, equipment and personnel. Although availability is an essential prerequisite, it does not guarantee the delivery of high-quality services (6). There is evidence regarding the availability of rehabilitation services. For example, a 2009 study conducted by Points in Canada indicated that there are approximately 4.8 physiotherapist (PTs) and 3.7 occupational therapists (OTs) for every 10,000 people (7). Another study in South America on the "Availability and Characteristics of Cardiovascular Rehabilitation Programs' indicated that there are 160 cardiovascular rehabilitation (CR) programs in nine of the 10 countries, as demonstrated by the South American Society of Cardiology, and there is approximately one CR program for every 2,319,312 inhabitants (8).

\subsection{Statement of the problem}

The prevalence of disability in Iran has increased due to war, road accidents, climate changes, natural disasters, population ageing, and chronic diseases $(1,9)$. Based on the available evidence, there are more than 500,000 veterans from the Iran /Iraq war, whom need rehabilitation services at present (10). Road accidents and trauma comprise the most significant cause of death and disabilities in Iran (11). Iran is one of 10 most accident-prone countries in the world, ranking fourth in Asia (12). During the past two decades, the growth rate of the country's aging population has increased from 1.3 to 3 (13). In addition, based on upper national plans such as Directives Communicated Policies by supreme leader Ayatollah Khamenei, and the Health Transformation Plan, universal coverage of rehabilitation services is considered as a priority (14). However despite these facts, rehabilitation is not considered as a priority to facilitate resources allocation; therefore, there is little funding for rehabilitation in Iran.

\subsection{Objective of research}

Lack of knowledge about number of rehabilitation`s staff and services in Iran was the cause of inappropriate decision making in education and distribution of staff throughout Iran. Therefore, this study aims to take as an example of rehabilitation services status in Iran in order to raise policy-makers' awareness towards allocation of resources for rehabilitation services.

\section{Material and Methods}

This research was approved by the Social Determinants of Health research center at the University of Social Welfare and Rehabilitation Sciences. Ethical approval was obtained from the University of Social Welfare and Rehabilitation Sciences Ethical Committee. This study adopted a two-phase exploratory sequential mixed method design. In the first phases, a qualitative has been conducted for designing an instrument for data gathering and then, in the second phase cross-sectional study was employed to determine the availability of all physical rehabilitation services. These two main phases are explained as follows.

\subsection{Qualitative phase}

In this phase, a qualitative content analysis was conducted for developing an instrument for data gathering in quantitative phase. In order to monitor the availability of rehabilitation services and provide recommendations to support the health system, the World Health Organization (WHO) has developed the Service Availability and Readiness Assessment (SARA) tool (10). In 2011, the WHO, in collaboration with the United States Agency for International Development (USAID), together with MEASURE DHS (monitoring and evaluation to assess and use results, demographic and health surveys), and International Classification of Functioning, Disability and Health (ICF), decided to develop an efficient tool to fill the critical gaps in measuring and tracking health system progress. The SARA instrument was developed to assess the availability of rehabilitation services. The rationales for using this tool are that it can be used to monitor the services rendered at different settings of health system and that it relies on a fast method of data collection and rapid analysis (6). This tool focuses on two main areas of healthcare entities - the availability of key healthcare service providers and the presence of health infrastructure resources 
(capacity of the system to provide health services). SARA has been used by two countries-Kenya and Sri Lanka-to assess the availability of health services (6). Initially, they used the Master Facilities List (MFL) as the starting point of the SARA. The MFL includes all governmental, public non-governmental and private centers. These health services include hospitals beds, health centers, and clinics. If the MFL is not available in a country, a preliminary list should be created with the help of the health management information system (15). Therefore, the SARA tool has been used to develop an MFL of rehabilitation services in Iran (6). Two focus groups were conducted in this phase. The researchers purposively selected sampling units based on their experience or knowledge about research questions. Therefore, we invited four representatives of relevant organizations, five academicians and three people as representatives of organizations for people with disabilities. We conducted sessions of focus groups in the Ministry of Health and Medical Education conference room. Prior to the interviews, the participants' consent was obtained. They were informed about the purpose of the study and were assured of confidentiality. In order to provide a list of rehabilitation of various services and identify human resources, we have used a semi-structured questionnaire with open-ended questions (4). Sample questions for focus group sessions include: "Which health system settings provide rehabilitation services?", "What services are offered at each setting?", and "What organizations provide rehabilitation services?". An inductive content analysis was used for analysing focus group interviews. Based on the results of the two focus group discussions, lists of existing rehabilitation services and rehabilitation service providers were obtained.

\subsection{Quantitative Phase}

In the second phase, a cross-sectional study was conducted between June and October 2015. We carried out data gathering with the MFL that was developed in the first phase. Sampling was by way of census and included all existing physical rehabilitation services in Iran. All governmental and private physical rehabilitation centers affiliated with the Ministry of Health and Medical Education, Ministry of Labor, Cooperative and Social Welfare, and the Iranian Red Crescent Society at different settings including inpatient, outpatient, community-based and long-term care-in 32 provinces in Iran were included. The inclusion criterion was that the service had to be a governmental or private center at inpatient, outpatient, community-based, or long-term care setting, operating since 2015. Data were collected from the statistics of the Deputy for Rehabilitation of Social Welfare Organization offices and the Deputy for Treatment of the Red Crescent Organization in 32 Iranian provinces. Three research assistants were employed to collect data in accordance with the MFL of the existing rehabilitation services and rehabilitation professionals. The MFL was mailed to 42 medical universities affiliated with the Ministry of Health in the provinces. Two members of the dissertation committee checked the data for accuracy, completeness, and internal consistency. Descriptive statistical analysis (percentage and frequency) were calculated for the nominal and ordinal data. The national data were analysed for the number of rehabilitation services (governmental and private centers) and the number of rehabilitation workers per 1,000,000 population. Statistical analysis was performed with SPSS Version 16 statistic software package.

\section{Results}

\subsection{Developing an MFL}

The content analysis of the data obtained from the focus group discussions identified the MFL of physical rehabilitation services. This list includes a variety of infrastructure and rehabilitation human resources. Rehabilitation infrastructure was divided into four settings - inpatient, outpatient, community-based, and long-term. Tracer indicators and items of services were selected in 1) inpatient: number of rehabilitation beds for every 1,000,000 people; 2) outpatient number of rehabilitation centers including physical medicine and rehabilitation clinics, physiotherapy clinics, occupational therapy clinics, speech therapy clinics, audiometry clinics, orthotic and prosthetic clinics, day-care centers, and vocational centers; 3 ) community-based setting home care rehabilitation and community-based rehabilitation (CBR) centers; and 4) long-term settings existed nursing homes for every 1,000,000 people (Table 1). Rehabilitation service providers include physical medicine and rehabilitation specialists, physiotherapists, occupational therapists, speech therapists, and audiologists (Table 1).

\subsection{Availability of rehabilitation Infrastructures}

At the inpatient setting, only 1.683 beds are allocated to every million people. There are only two rehabilitation hospitals in Iran, both located in Tehran. The majority of rehabilitation services are available through outpatient (89.243 for every million people) and community-based settings (66.214 for every million people). In outpatient settings, services-generally provided in clinics-mostly involve physiotherapy (29.616 for every million people). There are a few general rehabilitation clinics (1.144 for every million people). The interdisciplinary services are mainly provided in day-care rehabilitation centers (3.406 for every million people) followed by the vocational 
training centers ( 4.774 for every million people). At the community-based setting, accessibility of services is as follows: 64.228 community-based rehabilitation centers and 1.986 Home Healthcare Rehabilitation centers (for every million people). Finally, at long-term care setting, there are 3.603 Nursing Home centers for every million people (Table 2).

Table 1. Infrastructures and professionals providing physical rehabilitation services

\begin{tabular}{|c|c|c|}
\hline \multirow{3}{*}{$\begin{array}{l}\text { Domain } \\
\text { Health } \\
\text { infrastructure }\end{array}$} & \multicolumn{2}{|c|}{ Tracer indicators, items or services } \\
\hline & & Number of inpatient beds per $1,000,000$ population \\
\hline & \multirow{9}{*}{ Outpatient } & Number of rehabilitation center per $1,000,000$ population \\
\hline & & $\begin{array}{l}\text { Number of physical medicine \& rehabilitation office per } \\
1,000,000 \text { population }\end{array}$ \\
\hline & & Number of physiotherapy office per $1,000,000$ population \\
\hline & & $\begin{array}{l}\text { Number of occupational therapy office per 1,000,000 } \\
\text { population }\end{array}$ \\
\hline & & Number of speech therapy office per $1,000,000$ population \\
\hline & & Number of audiometry office per $1,000,000$ population \\
\hline & & $\begin{array}{l}\text { Number of orthotic\& prosthetic office per 1,000,000 } \\
\text { population }\end{array}$ \\
\hline & & Number of day care center per $1,000,000$ population \\
\hline & & Number of vocational center per $1,000,000$ population \\
\hline & \multirow{2}{*}{$\begin{array}{l}\text { Community center } \\
\text { rehabilitation }\end{array}$} & Number of home care center per $1,000,000$ population \\
\hline & & $\begin{array}{l}\text { Number of community base rehabilitation center per } 1,000,000 \\
\text { population }\end{array}$ \\
\hline & Long term care & Number of nursing homes per $1,000,000$ population \\
\hline \multirow[t]{5}{*}{ Health workforce } & \multicolumn{2}{|c|}{ Number of physical medicine \& rehabilitation per $1,000,000$ population } \\
\hline & \multicolumn{2}{|c|}{ Number of physiotherapist per $1,000,000$ population } \\
\hline & \multicolumn{2}{|c|}{ Number of occupational therapist per $1,000,000$ population } \\
\hline & \multicolumn{2}{|c|}{ Number of speech therapist per $1,000,000$ population } \\
\hline & \multicolumn{2}{|c|}{ Number of audiologist per $1,000,000$ population } \\
\hline
\end{tabular}

Table 2. The number of rehabilitation facilities per 1,000,000 populations in different service settings

\begin{tabular}{|c|c|c|c|c|}
\hline Setting & Various Facilities & Infrastructures & Number & $\begin{array}{l}\text { Average facility per } \\
1,000,000 \text { population }\end{array}$ \\
\hline Inpatient & Hospital & $\begin{array}{l}\text { Bed/Number of } \\
\text { Hospitals }\end{array}$ & 128.2 & 1.683 \\
\hline \multirow[t]{10}{*}{ Outpatient } & General rehabilitation center & Number of center & 87 & 1.144 \\
\hline & $\begin{array}{l}\text { Physical medicine and } \\
\text { rehabilitation offices }\end{array}$ & Number of clinic & 229 & 3.012 \\
\hline & Physiotherapy offices* & Number of clinic & 2252 & 29.616 \\
\hline & Occupational therapy offices & Number of clinic & 1036 & 13.624 \\
\hline & Speech therapy offices & Number of clinic & 12 & 15.939 \\
\hline & Audiology offices & Number of clinic & 1077 & 14.164 \\
\hline & $\begin{array}{l}\text { Orthotics and prosthetics } \\
\text { office }\end{array}$ & Number of clinic & 171 & 3.564 \\
\hline & Day care rehabilitation center & Number of center & 159 & 3.406 \\
\hline & Vocational training center & Number of center & 363 & 4.774 \\
\hline & Total & & 6586 & 89.243 \\
\hline \multirow[t]{3}{*}{$\begin{array}{l}\text { Community based } \\
\text { setting }\end{array}$} & $\begin{array}{l}\text { Home health care } \\
\text { rehabilitation center }\end{array}$ & Number of center & 151 & 1.986 \\
\hline & CBR center & Number bases & 48839 & 64.228 \\
\hline & Total & & 48990 & 66.214 \\
\hline Long term care & Nursing home & Number of centers & 274 & 3.603 \\
\hline
\end{tabular}

* Office that includes hospital-based outpatient units, health center and private clinics 
http://www.ephysician.ir

\subsection{Rehabilitation Service Providers}

The distribution of rehabilitation professionals is shown in Table 3. According to our findings, more physiotherapists are available (65 physiotherapists for every $1,000,000$ people) while there are fewer physical medicine and rehabilitation specialists (four specialists for every 1,000,000 people). The distribution of rehabilitation services in terms of the providing organization is shown in Table 4. Based on our data; inpatient services are mostly afforded by the Red Crescent Society with 1.026 beds for every million people. Considering outpatient setting, the Ministry of Health with 29.011 physiotherapists for every million people is the one that owns the highest number of services. In community-based and long-term care setting, the Social Welfare Organization has the highest coverage with 3.603 for every million people respectively (Figure 1).

Table 3. Number of human rehabilitation workforce

\begin{tabular}{|l|l|l|}
\hline Rehabilitation Staff & Number & Average rehabilitation staff per1,000,000 population \\
\hline $\begin{array}{l}\text { Physical medicine and rehabilitation } \\
\text { specialist }\end{array}$ & 297 & 3.905 \\
\hline Physiotherapist & 4916 & 64.650 \\
\hline Occupational therapist & 1680 & 22.094 \\
\hline Speech therapist & 1736 & 22.830 \\
\hline Audiologist & 1839 & 24.185 \\
\hline
\end{tabular}

Table 4. Distribution of rehabilitation facilities at different settings based on provider organization

\begin{tabular}{|l|l|l|l|l|}
\hline \multirow{3}{*}{ Setting } & Types of Facilities & \multicolumn{2}{|l|}{ Service Provider Organization } \\
\cline { 3 - 5 } & & $\begin{array}{l}\text { Ministry of Health and } \\
\text { Medical Education }\end{array}$ & $\begin{array}{l}\text { Social Welfare } \\
\text { Organization }\end{array}$ & $\begin{array}{l}\text { Red Crescent } \\
\text { Society }\end{array}$ \\
\hline Inpatient & Hospital & 0.658 & - & 1.026 \\
\hline \multirow{5}{*}{ Outpatient } & Rehabilitation center & 1.131 & - & 0.013 \\
\cline { 2 - 5 } & $\begin{array}{l}\text { Physical medicine and } \\
\text { rehabilitation specialist office }\end{array}$ & 3.012 & - & - \\
\cline { 2 - 5 } & Physiotherapist office & 29.011 & - & 0.605 \\
\cline { 2 - 5 } & Occupational therapy office & 13.467 & - & 0.158 \\
\cline { 2 - 5 } & Speech therapy office & 15.821 & - & 0.118 \\
\cline { 2 - 5 } & Audiology office & 14.137 & - & 0.026 \\
\cline { 2 - 5 } & $\begin{array}{l}\text { Orthotics and prosthetics } \\
\text { office }\end{array}$ & 3.275 & - & - \\
\cline { 2 - 5 } & Day rehabilitation centers & - & 3.406 & - \\
\cline { 2 - 5 } & Vocational training center & - & 1.986 & - \\
\hline \multirow{2}{*}{$\begin{array}{l}\text { Community } \\
\text { based setting }\end{array}$} & $\begin{array}{l}\text { Home health care } \\
\text { Rehabilitation center }\end{array}$ & - & 64.228 & - \\
\cline { 2 - 5 } & CBR center & - & 3.603 & - \\
\hline Long term care & Nursing home & - & \multicolumn{2}{|}{} \\
\hline
\end{tabular}




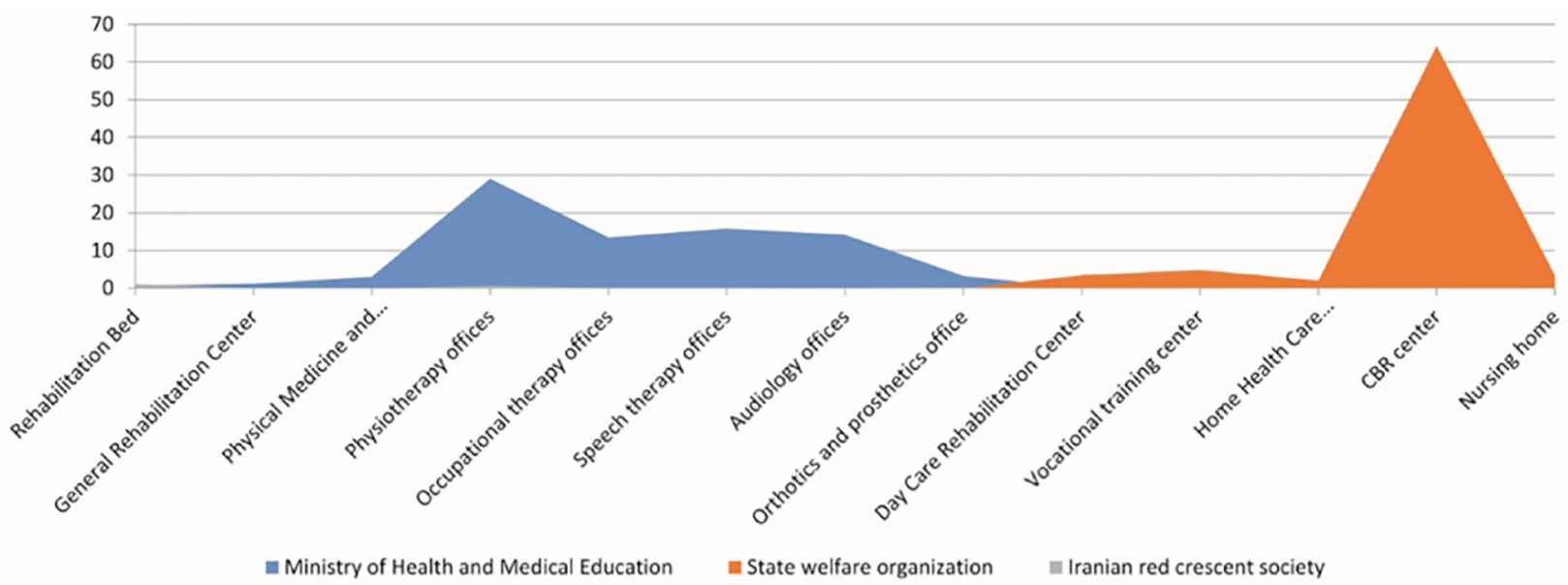

Figure 1. Distribution of rehabilitation facilities at different settings based on provider organization

\section{Discussion}

To discuss the availability of rehabilitation services at different settings, we chose to examine these findings in relation to the SARA tool as follows: Based on the SARA tool, availability of rehabilitation services was assessed in terms of 1) availability of rehabilitation infrastructures; 2) availability of rehabilitation professionals; and 3) allocation of rehabilitation services for each organization.

\subsection{Availability of rehabilitation infrastructures}

\subsubsection{Inpatient setting:}

In regard to inpatient rehabilitation services, the data show an average of 1.63 beds for every million people. Unfortunately, this facility is available in only two rehabilitation hospitals, both of them located in Tehran. Compared to developed countries such as Canada and Australia (with 18 and 24 inpatient rehabilitation beds for every million people, respectively), Iran has a long way to go (16). In a study by Hogan et al., the standard number of rehabilitation beds is estimated to be 0.1 for every 1,000 people (17). The British Society of Rehabilitation Medicine proposed a minimum of 60 rehabilitation beds for every million people (18). In Iran, the Shafa Hospital founded in 1971 is Iran's first rehabilitation hospital. In 1973, the Milad Hospital was established as an inpatient spinal cord injury rehabilitation center (9). Despite this promising start, the continuation of the process was not so favourable. Actually, the primary idea of the establishment of a rehabilitation hospital did not come true and after a while, Milad transformed to a general hospital. Deficient expansion in the number of rehabilitation beds, together with an increased elderly population and resulting increase in the number of non-communicable diseases have plunged the country into serious problems in this area. This shortage has led to the admission of rehabilitation patients in other hospital departments such as the orthopaedic ward, neurology department, etc. This can lead to an unfavourable service allocation and consequently, inefficient rehabilitation process. In a study on amputee rehabilitation, it was reported that patients who admitted to rehabilitation wards regained $33 \%$ physical function in one year. Surely, this target could not be met by the admission of patients to other wards (19). Considering the aforementioned standards, a minimum of 4,560 rehabilitation beds are needed in Iran.

\subsubsection{Outpatient setting:}

In Iran, rehabilitation services in the outpatient setting include General Rehabilitation center, physical medicine and rehabilitation specialists, physiotherapy, occupational therapy, speech therapy, audiology, orthotics and prosthetics office, day rehabilitation, and vocational training centers. Statistics show that majority of available rehabilitation infrastructures in an outpatient setting are in the form of non-governmental monodisciplinary clinics and only a small part is in the form of multidisciplinary day centers (3.406 for every million people). General Rehabilitation centers are even fewer in number (1.144 for every million people). According to the 2013 Health and Population Report, 14.9 day care centers are available for every million people in the US (20). The other point to be considered is the need for reinforcement of referral system between rehabilitation centers, day care centers, and communitybased services such as vocational training centers (18). There is no doubt that the integrated rehabilitation and consistent communication between the team members can lead to more qualified service provision and consequently, higher patient satisfaction through promotion of the whole system (18). This shortcoming needs to be eliminated in not only the outpatient setting but other settings as well. 


\subsubsection{Community-based setting:}

Based on the results of the current study, community-based rehabilitation setting faces a serious deficiency in infrastructures (only 1.98 Home Healthcare centers for every million people). Furthermore, some services such as hospice care and respite care are completely missing. In the US, the number of available home rehabilitation services is 37.9 home care centers and 11.5 respite centers (for every million people). The most expanded part of this setting is the community-based rehabilitation centers, in a ratio of 64.228 for every million people. In the last three decades, the global change in attitudes towards rehabilitation has brought about an evolution resulting in a shift from traditional rehabilitation to community-based rehabilitation services (18). In Iran, CBR was initially implemented in the form of primary healthcare; however, in the continuation of this project, the Social Welfare Organization succeeded in implementing CBR nationwide. In a 2004 study by Kamali et al. conducted in 14 provinces of the country, CBR had little effect on the ability of everyday life of clients in the initial implementation. This could be because this study was performed in the earlier years (21). In another study conducted in 2012, the mobility is found to be increased from $43.4 \%$ to $67.9 \%$ respectively (22). This clearly suggests that communitybased interventions will take their effect in a long-term period rather than immediately.

4.1.4. Long-term care setting:

In this section, nursing home centers are discussed. Generally, rehabilitation approach is towards support of disabled individuals who desire services in their own homes. But in some cases of severe disability and complete dependency, nursing home centers take the place of the patient's home (23). Therefore, provision of residential services such as nursing home centers or residential care centers for the disabled elderly is a necessity. Presently, in the US, 48.8 nursing homes and 69 assisted living homes are available (for every million people) (20).

\subsection{Availability of rehabilitation professional}

Clearly, health workforce plays a fundamental role in the health system. Often, in national programs in the health sector, evaluation of human resources is neglected and in most countries, information of the human rehabilitation staff is inadequate and fragmented. This could be due to the lack of common definitions and classifications, lack of available statistical information, lack of resources needed to monitor the workforce, and the lack of political determination, especially for evaluating rehabilitation professionals (24). Regarding availability of physical medicine specialists, despite the remarkable efforts in developing physical medicine and rehabilitation specialists in Iran and having a documented curriculum in this field, this course has unfortunately failed to expand in accordance to the needs of the country (9). Presently, in Croatia, there are 4.7 physical medicine specialists (for every million people), which is significantly higher than that of Iran (3.905 specialist for every million people) (25). Certainly, improvement in quality and quantity of specialists in this field needs and expansion in services such as inpatient beds and creation of infrastructures such as rehabilitation centers, together with a team of trained rehabilitation personnel (9). While different areas of rehabilitation such as neurology, orthopaedics, internal medicine, etc. are expanding worldwide, nothing significant has happened in this regard in Iran. Research fellowship programs in rehabilitation medicine are not defined so far, and the field of rehabilitation is not addressed in the course of general medicine. In terms of availability of other members of the rehabilitation team, the highest ratio is accounted to physiotherapy (64.65), followed by occupational therapy (22.09), speech therapy (22.83), and audiology (24.18) respectively for every million people. According to the British standards of inpatient rehabilitation professionals, for every 20 beds, 1.2 specialists in rehabilitation medicine, 2 or three trained general practitioners, 24-30 nurses, 4 physiotherapists, 4 occupational therapists, and 2-2.5 speech therapists are required. At the setting of outpatient and community-based care, for every million people, 8 rehabilitation nurses, 6 physiotherapists, and 10 occupational therapists are needed. According to a report published by the WHO in 2008, for every 10,000 people in the US, there are 5.5 physiotherapists. For some other countries, this number is as follows: Australia: 5.3; Canada: 4.9; Great Britain: 4.5; Panama: 1.3; South Africa: 1.3; Tunisia: 1.2; Zambia: 0.17; Indonesia: 0.07; Uganda: 0.04; Mali: 0.03; and Burkina Faso: 0.02 (24). For Iran, in 2015, this number was 0.6. As another example, in the year 2000, the number of occupational therapists and speech therapists in the US, was 13.8 and 27.3 respectively for every 100,000 people (26). In another study conducted in 2007, it was reported that the ratio of physiotherapists and occupational therapists in Canada, was 4.8 and 3.7 respectively (for every 10,000 people) (7). The above statistics imply the shortage of rehabilitation professionals in all disciplines. It also represents the disproportion between the needs of society and the rehabilitation workforce. Therefore, the need for policy formulation and the establishment of standard educational programs for rehabilitation professionals and provision of needed infrastructures and services have become more apparent. 


\subsection{Availability of services in provider organizations}

A glance at Table 4 shows us that rehabilitation services are provided by different organizations at different proportions. Unfortunately, no connection has been defined between these different settings and various organizations; hence, services cannot be delivered in the form of a chain. According to WHO recommendations; the Ministry of Health and Medical Education and its affiliated agencies are responsible for facilitating these intersectoral relations. International Action for Health (IAH) includes the connection between different service providers with the aim of development of health services and the use of capacities available outside the health system (27). Presently, major challenges in the rehabilitation field are lack of administrator, lack of strategy and program planning, and lack of vision regarding the patient's problems. Integrated care is a concept that brings together inputs, delivery, management, and organization of services related to diagnosis, treatment, care, rehabilitation, and health promotion (28). Considering the above issue and in order to provide a satisfactory universal coverage, integration should be implemented in rehabilitation services.

\subsection{Limitation}

Unfortunately, because of incomplete data registration, we were not able to calculate the Service Utilization Indexanother measure of service availability. This could be a limitation of our study.

\section{Conclusions}

In Iran, rehabilitation services are under the supervision of various organizations of various settings. The lack of proper coordination between these organizations results in disintegrated information, especially in regard to the availability of rehabilitation services.

\section{Acknowledgments:}

This paper is based on a $\mathrm{PhD}$ research at the University of Social Welfare and Rehabilitation Sciences. The authors would like to express their deep gratitude to the following organizations: The Ministry of Health and Medical Education, the Social Welfare and Rehabilitation Organization, the Red Crescent Organization, and the Department of Statistics-Medical System Organization. The authors sincerely thank Dr. Mohsen Poursadeghiyan (Assistant Professor of Department of Ergonomics, Pediatric Neurorehabilitation Research Center, University of Social Welfare and Rehabilitation Sciences, Tehran, Iran), for his guide and cooperation.

\section{Conflict of Interest:}

There is no conflict of interest to be declared.

Authors' contributions:

All authors contributed to this project and article equally. All authors read and approved the final manuscript.

\section{References:}

1) World Health Organization, World Bank. World report on disability. Geneva: World Health Organization; 2011.

2) Pruitt S, Canny J, Epping-Jordan J. Preparing a health care workforce for the 21 st century. the challenge of chronic conditions: World Health Organization; 2005.

3) Behzisti. State welfare organization 2015. Available from: http://www.behzisti.ir/.

4) Krueger RA, Casey MA. Focus groups: A practical guide for applied research. Sage publications; 2014.

5) World Health Organization. Service availability and readiness assessment (SARA): an annual monitoring system for service delivery: reference manual. 2014.

6) World Health Organization. What is universal coverage: World Health Organization; 2014. Available from: http://www.who.int/health_financing/universal_coverage_definition/en/.

7) Landry MD, Cott CA, Deber R, Cameron J, Zack E. Policy Brief: Availability of Rehabilitation Services Along Ontario's Continuum of Care. Toronto, Ontario: The Rehabilitation Policy \& Health Human Resource Research Unit; 2009.

8) Cortes-Bergoderi M, Lopez-Jimenez F, Herdy AH, Zeballos C, Anchique C, Santibañez C, et al. Availability and characteristics of cardiovascular rehabilitation programs in South America. J Cardiopulm Rehabil Prev. 2013; 33(1): 33-41. doi: 10.1097/HCR.0b013e318272153e. PMID: 23235320.

9) Raissi G, Ahadi T, Forogh B, Manesaz E. Status of the Physical Medicine and Rehabilitation in the Health system and Medical Education. Journal of Medical Council of Iran. 2012; 30(1): 78-9. 
10) Zarei Matin H, Jandaghi G, Heydari F, Imani $M$. The attitude of war handicaped toward the services recieved in terms of their needs. Iranian Journal of War and Public Health. 2010; 2(2): 22-31.

11) Yousefzadeh S, Dafchahi MA, Maleksari HM, Moghadam AD, Hemati H, Shabani S. Epidemiology of Injuries and their causes among traumatic patients admitted into Poursina hospital, Rasht. J Kermanshah Univ Med Sci. 2007; 11(3): 286-95.

12) Ojaghi S, Nourizad S, Mahboobi M, Khazaei M, Najafi G. Disaster crisis handling preparedness level of hospitals in Kermanshah. J Kermanshah Univ Med Sci. 2009; 13(3).

13) The draft document of national strategic plan csPcA. 2011. Available from: http://www.behzisti.ir/downloads/bulletins/Bulletin0010.pdf. U.

14) Directives Communicated Policies. The Office of the Supreme Leader Sayyid Ali Khamenei; 2014. Available from: http://www.farsi.khamenei.ir/news-content?id=26083.

15) O'Neill K, Takane M, Sheffel A, Abou-Zahr C, Boerma T. Monitoring service delivery for universal health coverage: the Service Availability and Readiness Assessment. Bull World Health Organ. 2013; 91(12): 923-31. doi: 10.2471/BLT.12.116798. PMID: 24347731, PMCID: PMC3845262.

16) Ministry of Health and Long-Term Care. Annual Report of the Office of the Auditor General of Ontario. Rehabilitation Services at Hospitals. $2013 . \quad$ Available from: http://www.auditor.on.ca/en/content/annualreports/arreports/en13/308en13.pdf.

17) Hogan PF, Dobson A, Haynie B, DeLisa JA, Gans B, Grabois M, et al. Physical medicine and rehabilitation workforce study: the supply of and demand for physiatrists. Arch Phys Med Rehabil. 1996; 77(1): 95-9. doi: 10.1016/S0003-9993(96)90228-2. PMID: 8554483.

18) Medical rehabilitation in 2011 and beyond. London. Royal college of Physicians \& British Society of Rehabilitation Medicine. 2010.

19) Kurichi JE, Small DS, Bates BE, Prvu-Bettger JA, Kwong PL, Vogel WB, et al. Possible incremental benefits of specialized rehabilitation bed units among veterans after lower extremity amputation. Med Care. 2009; 47(4): 457. doi: 10.1097/MLR.0b013e31818b08c6. PMID: 19238103, PMCID: PMC2865891.

20) Harris-Kojetin L, Sengupta M, Park-Lee E, Valverde R. Long-Term Care Services in the United States: 2013 Overview. Vital Health Stat 3. 2013; (37): 1-107. PMID: 26158640.

21) Kamali M. The Rehabilitation status in the structure of the comprehensive welfare and social security. 2006. Available from: http://www.mkamali.com/mainfa/articles/public/nezam\%20refah.pdf.

22) Nasiripour AA, Tabibi J, Afkar A, Kamali M. Effect of Community Based Rehabilitation Program Implementation on Disabled People Living Conditions in Iran. Journal of Knowledge \& Health. 2012; 7(4): 173-8.

23) Salarvand S, Abedi HA. Causes and motivations of elderly home residency from residents' point of view. Feyz Journals of Kashan University of Medical Sciences. 2008; 12(2).

24) World Health Organization. Monitoring human resources for health-related rehabilitation services 2009. Available from: http://www.who.int/hrh/statistics/spotlight_7_en.pdf.

25) Bakran Z, Bobinac-Georgievski A, Dzidic I, Jelic M, Eldar R. Medical rehabilitation in croatia-impact of the 1991-1995 war: past problems, present state, future concerns. Croat Med J. 2001; 42(5): 556-64. PMID: 11596173.

26) Wilson RD, Lewis SA, Murray PK. Trends in the rehabilitation therapist workforce in underserved areas: 1980 - 2000. J Rural Health. 2009; 25(1): 26-32. doi: 10.1111/j.1748-0361.2009.00195.x. PMID: 19166558.

27) World Health Organization. Challenging inequity through health systems. 2007. Available from: http://www.who.int/social_determinants/resources/csdh_media/hskn_final_2007_en.pdf.

28) Gröne O, Garcia-Barbero $\bar{M}$, WHO European Office for Integrated Health Care Services. Integrated care: a position paper of the WHO European office for integrated health care services. Int J Integr Care. 2001; 1: e21. doi: 10.5334/ijic.28. PMID: 16896400, PMCID: PMC1525335. 